\title{
Fernando Pessoa e as Glórias Pretendidas
}

Maria da Glória Ferreira de Sousa ${ }^{1}$

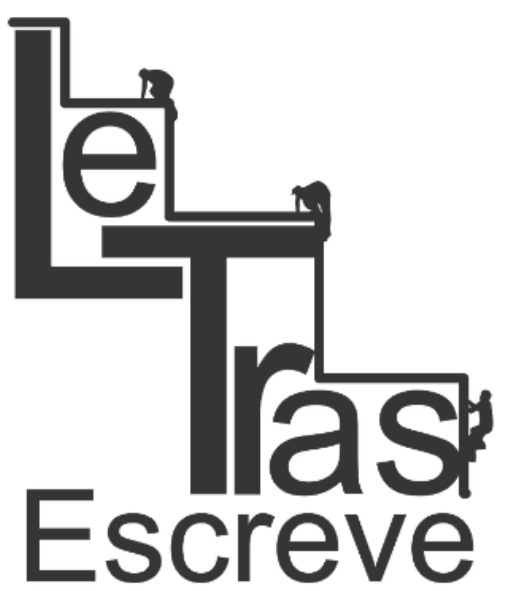

(ISSN 2238-8060)

Resumo: Tendo produzido uma obra heterônima que chama a atenção pelas suas múltiplas visões do espírito humano, Fernando Pessoa é dono de uma obra ortônima também extremamente densa, tal é o caso de Passos da Cruz, no qual se percebe um intenso desejo do eu-lírico de que sua poesia permaneça na eternidade. Tomando como base essa obra, formada de quatorze sonetos claramente alusivos as quatorze estações da via sacra vivida por Jesus, este trabalho tem por finalidade esclarecer acerca dessas aspirações de imortalidade pretendida pelo eu-lírico, imortalidade essa a ser conquistada através dos mais variados artifícios e, muitas vezes, lamentada por não se configurar nitidamente à frente daquele que a almeja. O percurso do poeta é, no mais das vezes, sofrido, angustiado diante da impossibilidade de se fazer grande. A presente análise nos confronta com essa caminhada que vacila entre momentos de glória e de ruína, com a inquietação característica de vários poemas pessoanos, com a genialidade desse poeta múltiplo, que é capaz de nos fazer repensar a nossa própria trajetória enquanto seres findos, ordinários perante a imortalidade do tempo.

Palavras-chave: Passos da Cruz. Percurso. Eternidade

Abstract: Author of heteronym literary works which call attention for his multiples views of the human soul, Fernando Pessoa is the owner of an orthonymous production that is also extremely dense. This is the case of Passos da Cruz, in which we can perceive an intense will of eternity. Based on this work, formed by fourteen sonnets clearly allusive to the fourteen stations of the Via Crucis, this article aims to clarify about the poet's aspirations of immortality, goal to be conquered through the most varied tricks and, many times, grieved for not being shown to that one who seeks to it. The poet's trajectory is also tough and anguished before the impossibility of increasing. This analysis puts us facing this path, which vacillates between glorious and ruined moments, with the characteristic inquietude of many Pessoa's poems and the geniality of this multiple poet, able to make us to think about our own way as finite beings, ordinary before the immortality of time.

Key-words: Passos da Cruz. Trajectory. Eternity.

\section{Fernando Pessoa e a elaboração de uma poesia missionária}

Fernando Antônio Nogueira Pessoa é, sem dúvida, uma das maiores personalidades do século $X X$ e sua poesia pode ser classificada como um patrimônio que permanecerá como um marco

\footnotetext{
${ }^{1}$ Mestre em Literatura Comparada pelo Programa de Pós-Graduação em Letras/Universidade Federal do Ceará. E-mail: mariadgfreire@gmail.com.
}

https://periodicos.unifap.br/index.php/letras

Macapá, v. 6, n. I, Io semestre, 2016. 


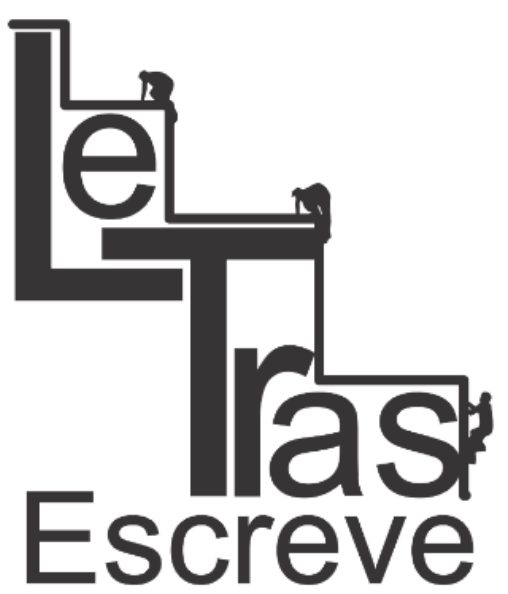

(ISSN 2238-8060)

de originalidade e singularidade dentre as obras primas produzidas pela humanidade.

Pessoa produziu uma obra heterônima altamente reconhecida pelas suas visões diversas do caráter humano, mas também produziu uma obra ortônima - de Fernando Pessoa-ele-mesmo peculiar e tão variada quanto, tal é o caso do nacionalista Mensagem, de Chuva Oblíqua e do impetuoso Passos da Cruz. Em todas essas produções o que se percebe é um eu-lírico apaixonado, afundado nas suas memórias - ou na memória de seu país - nas suas reflexões e nas suas conjecturas. Além disso, percebe-se também uma intensa vontade desse eu-lírico de pertencer a um elevado nível de grandeza, um desejo de que sua poesia permaneça na eternidade, o que nos remeterá à própria personalidade desse poeta, extremamente dedicado à arte de escrever.

Ainda criança e durante a adolescência, Pessoa mostra-se desejoso de alcançar tal plano de magnitude. Nas palavras de Maria José de Lancastre "Como para todos os artistas que fizeram da sua obra o objetivo e a ambição máxima da sua vida, talvez na biografia de Fernando Pessoa se possa encontrar aquilo que the aconteceu e aquilo que ele quis que fosse." (LANCASTRE, 1985).

Pessoa foi um dos alunos mais brilhantes da escola que freqüentou, sendo, inclusive, ganhador de vários prêmios escolares como o "Queen Memorial Victorian Prize", por um ensaio apresentado ainda durante a sua estadia na África do Sul. Em Portugal, opta por trabalhar apenas meio período a fim de poder dedicar-se mais à Literatura e não só isso, opta também por uma vida solitária, sem a trivial companhia de uma esposa, filhos e amigos. Inspira-se em grandes nomes como Shakespeare e Camões e escolhe também o inglês como forma de comunicação, como num anseio de poder abarcar um público maior e mais preparado culturalmente para o que haveria de criar. Pessoa também foi um dos participantes do movimento que alterou profundamente a cultura portuguesa de seu tempo, o Orfismo. Não

https://periodicos.unifap.br/index.php/letras Macapá, v. 6, n. I, Io semestre, 2016. 


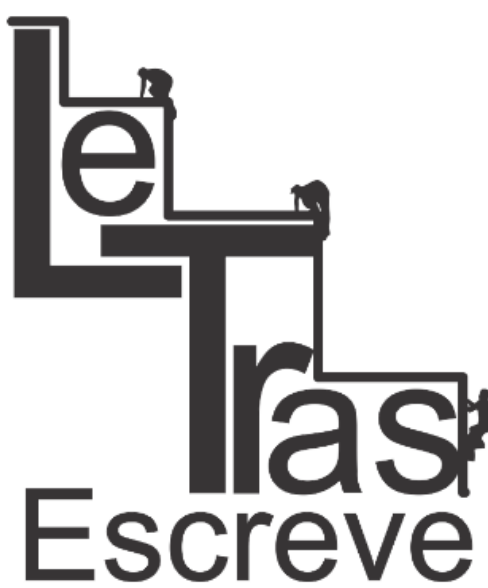

(ISSN 2238-8060) bastasse isso para que seu nome fosse gravado definitivamente na história da Literatura, a criação dos heterônimos constitui-se como um processo único. Além do mais, a escolha dos temas com os quais trabalha envolvem aspectos que dizem respeito à natureza humana de um modo geral, "reflete os grandes temas da Literatura de todos os tempos: a representação da

representação de Shakespeare, o tema faustiano, a angústia do conhecimento, a metafísica do real." (LANCASTRE, 1985).

Essa busca pela perpetuação estará presente em Passos da Cruz, do qual alguns poemas serão analisados neste trabalho, a saber das aspirações de eternidade pretendidas pelo seu eu-lírico, eternidade essa a ser conquistada através dos mais variados artifícios e, muitas vezes, lamentada por não se transfigurar claramente à frente do poeta.

Passos da Cruz constitui-se de um conjunto de quatorze sonetos publicados pela primeira vez em 1916 na revista Centauro. Mais tarde, tais poemas foram reunidos por Casais Monteiro para a editora Ática e mantidos em unidade. Claramente alusivos às quatorze estações da Via Sacra vivida por Jesus, seus poemas não são numerados, mas apenas dispostos em uma sequência na qual uma conexão entre os sonetos pode ser percebida. Aí, o poeta se coloca como um ser imbuído de uma missão, de uma cruz que terá de carregar durante todo o seu percurso literário, já que este encargo envolve Literatura e vida e não há certezas sobre sua concretização.

Apesar de estruturar seus poemas com base no sofrimento de Cristo na sua Santa Peregrinação, considerando-se um escolhido, um predestinado a levar a cabo sua missão, nenhuma outra referência é feita a esses episódios bíblicos, a não ser se considerarmos a presença de alguns elementos notadamente cristãos, tais como a hóstia consagrada e o deserto quaresmal. À exceção disso, Passos trata única e exclusivamente dos passos de

https://periodicos.unifap.br/index.php/letras Macapá, v. 6, n. I, Io semestre, 2016. 
um poeta na busca do cumprimento do seu destino, ainda que este se demore a lhe ser revelado por inteiro.

\section{O desejo do eterno em Passos da Cruz}

Todos os poemas de Passos da Cruz vêm até nós sob a forma de sonetos, clássica via de expressão literária que tem sobrevivido através dos séculos, quase sempre considerado como uma forma nobre de se fazer literatura. Não bastasse isso, é um dos gêneros mais praticados no Ocidente. Nota-se, desde já, que a escolha de tal veículo já parece prenunciar uma intenção de permanência, de conservação do que se está sendo criado.

O primeiro soneto de Passos nos apresenta um ambiente permeado de elementos da natureza, o que remonta alguns traços da Literatura Arcádica:
Esqueço-me das horas transviadas... O Outono mora mágoas nos outeiros E põe um roxo vago nos ribeiros... Hóstia de assombro a alma, e toda estradas...
Aconteceu-me esta paisagem, fadas
De sepulcros a orgíaco... Trigueiros
Os céus da tua face, e os derradeiros
Tons do poente segredam nas arcadas...
No claustro sequestrando a lucidez
Um espasmo apagado em ódio à ânsia
Põe dias de ilhas vistas do convés
No meu cansaço perdido entre os gelos, $E$ a cor do Outono é um funeral de apelos Pela estrada da minha dissonância...

Tal paisagem simplesmente "acontecera" ao poeta, ou seja, este não tivera o direito de escolher a sua permanência ali. Este parece ser o primeiro encontro do poeta com a missão que o levará dali por diante. A união de elementos alegres e sombrios parece atestar que tal missão é feita de aspectos compensatórios e outros nem tão compensatórios assim: "Aconteceu-me esta paisagem, 


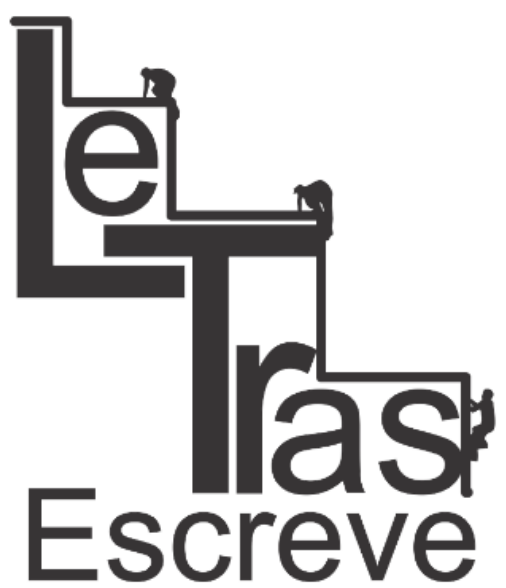

(ISSN 2238-8060) fadas/ De sepulcros a orgíaco...", "E a cor do outono é um funeral de apelos". Assim também a alma do poeta é "hóstia de assombro", fato paradoxal se levarmos em conta que a hóstia é considerada elemento de purificação. Isso nos faz crer que o poeta não faz uma boa imagem de sua própria essência, quando diante das estradas que tem a percorrer. O poeta parece, na verdade, cansado apenas diante de traçar esse caminho, o que nos torna à ideia de missão como fardo. A única coisa que resta ao eu-lírico é tentar recobrar a "lucidez" e seguir, mesmo com todos os obstáculos, pela estrada da sua "dissonância", pelo caminho de suas incoerências.

Daí por seguinte o que se vê é a confirmação da missão conferida pelo poeta: "Há um poeta em mim que Deus me disse" (Passo II), e o trilhar de seu caminho, muitas vezes em um ambiente onírico, cheio de grandezas e glórias, como podemos verificar em alguns versos do terceiro Passo:
O íntimo silêncio das opalas
Conduz orientes até jóias caras,
$\mathrm{E}$ o meu anseio vai nas rotas claras
De um grande sonho cheio de ócio e salas.
Passa o cortejo imperial, e ao longe
O povo só pelo cessar das lanças
Sabe que passa o seu tirano, e estruge
Sua ovação, e erguem as crianças...
Mas no teclado as tuas mãos pararam
E indefinidamente repousaram...

Aqui, o eu-lírico se coloca entre riquezas de um império grandioso, entre "jóias caras" e "ócio e salas". Imagina-se inserido em um cortejo imperial, ovacionado pelo povo, em um lugar onde sua autoridade se mostra incontestável, onde lanças cessam para que passe, crianças são içadas e, assim, o sonho vai seguindo até o momento em que o poeta pára de escrever. Tem-se, então, a interrupção de todas as honrarias quando o escritor cessa sua produção; o prestígio só existe enquanto existe poesia: o poeta só

https://periodicos.unifap.br/index.php/letras

Macapá, v. 6, n. I, Io semestre, 2016. 
se fará grande, quando da sua missão, quando cria. E esta parece ser a razão pela qual escreve.

No sexto Passo, entretanto, a imagem que o poeta faz de si mesmo é totalmente diferente da citada anteriormente.

Hoje sou a saudade imperial

Do que já na distância de mim vi...

Eu próprio sou aquilo que perdi...

E nesta estrada para Desigual

Florem em esguia glória marginal

Os girassóis do império que morri...

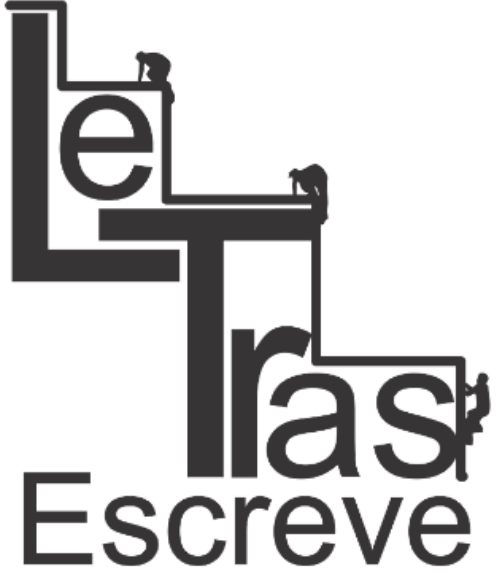

(ISSN 2238-8060)

Fosse eu uma metáfora somente

Escrita nalgum livro insubsistente

Dum poeta antigo, de alma em outras gamas,

Mas doente, e, num crepúsculo de espadas,

Morrendo entre bandeiras desfraldadas

Na última tarde de um império em chamas...

Era preferível ser somente uma metáfora, escrita em um livro sem valor, a encarar a situação que se lhe apresenta, a marginalidade na qual fora colocado. Mais uma vez, a missão literária do poeta se põe como superior, como nobre, ao mesmo tempo em que o eu-lírico de Passos é invadido novamente pela dor, pela "doença", em um império que já não é glória, mas apenas "chamas". Ainda assim, a morte é preferível à derrota, ao fim do seu império. As imagens suscitadas no último terceto trazem à tona toda uma situação de aflição causada mais uma vez pelo fato de o eu- 


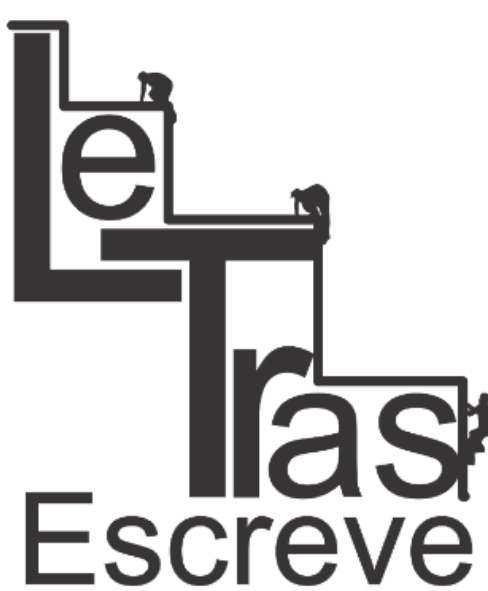

(ISSN 2238-8060) lírico não pertencer a nenhum mundo: o "crepúsculo de espadas" remete à tortura, à paixão pela qual passa o poeta.

O poeta segue a sua caminhada por entre paisagens que só existem dentro de si, muitas delas envolvidas pela destruição, pela escuridão só em alguns momentos superados pela luz: luz "De sombra e luz ocasional, e gritos/ Vagos ao longe, e assomos passageiros" (Passo X). E, carregando a sua cruz, o poeta vai tentando se encontrar, mas encontra-se apenas deserto, comparando-o ao mesmo deserto em que Deus/Jesus se refugiara por dias: "Narrei-me à sombra e não me achei sentido. / Hoje sei-me o deserto onde Deus teve / Outrora a sua capital de olvido...

O poeta é deserto porque não acha sua própria essência e é deserto porque fora esquecido. É esse esquecimento uma das principais fontes de agonia para o eu-lírico, talvez causa maior ainda que a própria despersonalização que atesta ter sofrido. São as glórias que mantêm de pé a entidade poeta, tenham estas vindo no presente ou apenas lembradas como tempos de felicidade.

Mas esse sofrimento parece, então, tomar golpes de esperança no Passo Seguinte. Tocado por uma instância exterior a ele mesmo, o poeta deixa-se inspirar, e seus versos, até aquele momento, já mortos porque já não esperavam, vão se transfigurando em versos cheios de perspectivas.

Não sou eu quem descrevo. Eu sou a tela

E oculta mão colora alguém em mim.

Pus a alma no nexo de perdê-la

E o meu princípio floresceu em Fim.

O poeta parece se dar conta do precipício no qual estava prestes a cair, tendo, então, renovado o seu processo de existência. Note-se a ambiguidade desenhada no último verso: o princípio do eu-lírico ou o seu renascimento floresce "em Fim", mas esse fim não parece trazer a significação de algo que se encerra, que finda, mas a significação de algo que "enfim" se fez realidade.

https://periodicos.unifap.br/index.php/letras

Macapá, v. 6, n. I, Io semestre, 2016. 
Essa ideia de desopressão por algo ter, finalmente, se realizado se confirma nos últimos tercetos do décimo primeiro Passo:

Disperso... E a hora como um leque fecha-se...

Minha alma é um arco tendo ao fundo o mar...

O tédio? A mágoa? A vida? O sonho? Deixa-se...

E, abrindo as asas sobre Renovar,

A erma sombra do voo começado

Pestaneja no campo abandonado...

A alma do poeta, aqui, já não é hóstia de assombro", mas uma alma que tem como fundo o mar, vastidão de algo que é vivo, que vibra. Todo o "tédio", a "mágoa", a "vida", o "sonho" que o acompanharam até ali na sua busca atormentada "Deixa-se...". O

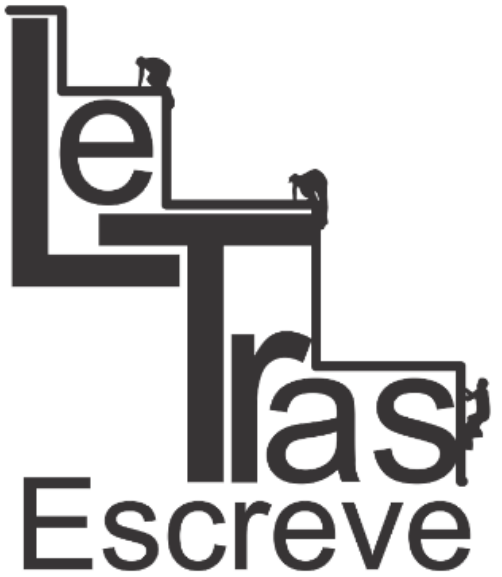

(ISSN 2238-8060) objetivo agora é recomeçar, "Renovar", vindo com letra maiúscula à maneira dos simbolistas, considerando também que simbolismo faz parte da própria essência de Passos. Esse sentimento de renovação seguir-se-á até culminar na plena afirmação da missão de que o poeta foi imbuído, porque é essa missão que Ihe conferirá a tão almejada eternidade.

\footnotetext{
Emissário de um rei desconhecido

Eu cumpro informes instruções de além,

$E$ as bruscas frases que aos meus lábios vêm

Soam-me a um outro e anómalo sentido...

Inconscientemente me divido

Entre mim e a missão que o meu ser tem,

$\mathrm{E}$ a glória do meu Rei dá-me o desdém

Por este humano povo entre quem lido...

Não sei se existe o Rei que me mandou.

Minha missão será eu a esquecer,

Meu orgulho o deserto em que em mim estou...

Mas há! Eu sinto-me altas tradições

De antes de tempo e espaço e vida e ser...

Já viram Deus as minhas sensações...
} 


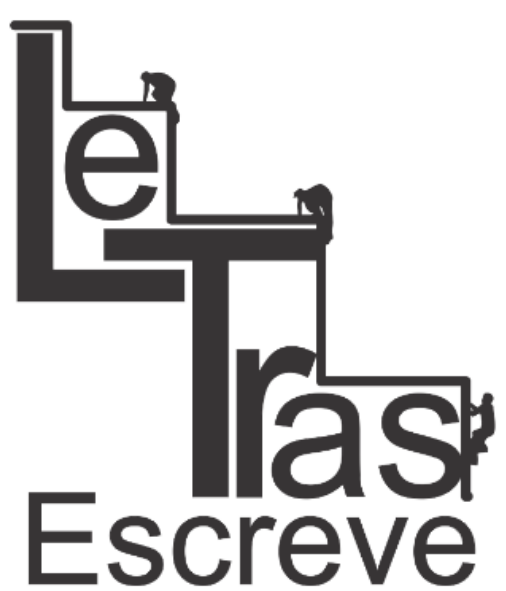

(ISSN 2238-8060)

O poeta desconhece aquele que lhe conferiu sua missão, afirmando apenas cumprir ordens de um ser que cuja compreensão não alcançaríamos. Obviamente, isso eleva sua incumbência a um nível superior a qualquer coisa, o que acaba por também elevar o próprio poeta, emissário que age através das suas letras, a um status também excelso, sobre-humano. E o poeta se envaidece disso e reconhece a sua superioridade entre aqueles a quem fora mandado pregar "E a glória do meu Rei dá-me o desdém/ Por este humano povo entre quem lido..." É interessante observar a colocação do adjetivo "humano" neste último verso. Essa adjetivação conferida a "povo" só enfatiza essa posição do eu-lírico, que não pertenceria, ou, pelo menos, deseja ardentemente não pertencer ao mundo natural. O povo é, portanto, colocado em uma instância de exterioridade e o poeta não o reconhece como fazendo parte de tal instância.

Além disso, o poeta também reconhece esse afastamento quando se sente "tradições" que escapam a nossa capacidade de reconhecimento do "tempo" ou do "espaço" ou mesmo a qualquer outro tipo de compreensão de mundo. Tais sensações, afirma ele, já viram "Deus", um Deus que não é necessariamente o Pai da cristandade, mas, talvez, o mesmo Rei que instigara o poeta a cumprir sua missão, o gênio inspirador de toda a sua poesia. Esta parece ser a missão do eu-lírico: a sua poesia. É só através dela, dessas "bruscas frases" que aos seus "lábios vêm", que poderá alcançar o eterno, a imortalidade que tanto ambicionou e que tanto o fizera sofrer.

O último soneto de Passos deixa-nos uma sensação de paralisia. A voz que impulsionara o poeta até então, cessa, e este nos revela que ela nascera apenas do seu tédio, do sonho.

Como uma voz de fonte que cessasse (E uns para os outros nossos vãos olhares Se admiraram), p'ra além dos meus palmares De sonho, a voz que do meu tédio nasce 


\author{
Parou... Apareceu já sem disfarce \\ De música longínqua, asas nos ares, \\ O mistério silente como os mares, \\ Quando morreu o vento e a calma pasce... \\ A paisagem longínqua só existe \\ Para haver nela um silêncio em descida \\ P'ra o mistério, silêncio a que a hora assiste... \\ $\mathrm{E}$, perto ou longe, grande lago mudo, \\ O mundo, o informe mundo onde há a vida... \\ E Deus, a Grande Ogiva ao fim de tudo...
}

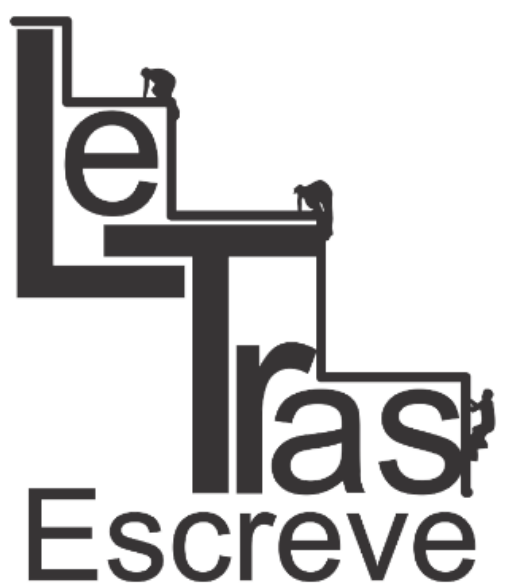

(ISSN 2238-8060)

A luta o poeta parece, então, adormecer. Da missão que tinha só resta o mistério, silencioso, apascentado. O mundo agora é um "lago mudo", sem impérios, já sem a possibilidade de glórias, sem a possibilidade do eterno. Tudo cessara, todos os desejos almejados e lamentados já não existem, não passaram de um sonho de alguém que ambicionara ser grande, ser superior, ser imortal. Mas mesmo no fim, a instância "Deus" permanece como uma grande "Ogiva", capaz de arrasar qualquer anseio, qualquer aspiração, mas que dessa forma também pode fazer nascer. É dessa maneira que o último verso do poema traz também um fio de esperança ao poeta, porque o "Deus" que finda é também o "Deus" eu principia e "Ele" pode trazer de novo à tona os desejos do eu-lírico.

\section{Passos da Cruz e as glórias pretendidas}

O eu-lírico de Passos da Cruz caracteriza-se por uma busca persistente da glória, por aquilo que o faria não findar jamais. Essa busca, motivada pela missão que recebera, acaba por separá-lo do mundo em que tem origem, do mundo físico, real. Tem-se, assim, um eu-lírico que se vê como um ser diferenciado, um predestinado à tarefa do professamento de algo que, naquele momento, seria desconhecido ao próprio ser que professa, mas que parece se delinear ao longe já no fim da sua caminhada.

Deste modo, Passos da Cruz também apresenta um poeta que sofre, que não está realmente integrado ao mundo ao qual 
deveria perceber como seu, que é diferente de tudo o que nele existe, incluindo aí, seus semelhantes. O que o tornaria superior é, também, causa do seu padecimento. Por isso, além de refletir sobre aquilo que é exterior a si mesmo, ele também se indaga sobre a sua existência e de que ela é feita. Isso se dá, principalmente, quando diante da possibilidade de não alcançar seus "impérios", sua imortalidade, de não se tornar "eterno". É essa a Paixão que permeia Passos da Cruz. Obviamente, como todas as obras de Fernando Pessoa, essa coletânea de poemas oferece e merece muitas outras interpretações. Esta é apenas mais uma, que, coincidentemente ou não, acaba por se assemelhar à trajetória do próprio Pessoa, um gênio das letras que se dedicou a ser um grande "imortal" da Literatura Universal.

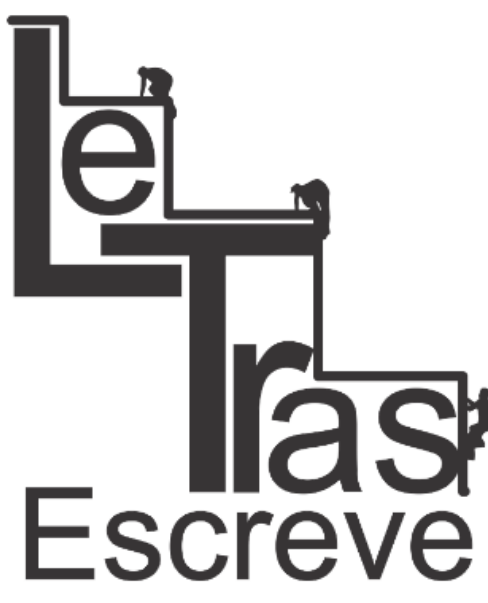

(ISSN 2238-8060)

\section{Referências bibliográficas}

GOLDSTEIN, Norma. Versos, sons, ritmos. São Paulo: Ática, 2002. LANCASTRE, Maria José de. O essencial sobre Fernando Pessoa. Lisboa: Casa da Moeda, 1985.

PESSOA, Fernando. Antologia poética. Int. e seleção de Walmir Ayala. $2^{a}$ ed. reform. São Paulo: Ediouro, 2001. - (Coleção antologias).

Recebido em 16/07/2016. Aprovado em 07/08/2016. 